\title{
Direct NMR Probing of Hydration Shells of Protein Ligand Interfaces and Its Application to Drug Design
}

\author{
Leonhard Geist, ${ }^{\dagger}$ (i) Moriz Mayer, ${ }^{\ddagger}$ Xiao-Ling Cockcroft, ${ }^{\ddagger}$ Bernhard Wolkerstorfer, ${ }^{\ddagger}$ Dirk Kessler, ${ }^{\ddagger}$ \\ Harald Engelhardt, ${ }^{\ddagger}$ Darryl B. McConnell,
}

${ }^{\dagger}$ Christian Doppler Laboratory for High-Content Structural Biology and Biotechnology, Department of Structural and Computational Biology, University of Vienna, Campus Vienna Biocenter 5, A-1030 Vienna, Austria

${ }^{\ddagger}$ Boehringer Ingelheim RCV GmbH \& Co. KG, Dr.-Boehringer-Gasse 5-11, A-1121 Vienna, Austria

\section{Supporting Information}

ABSTRACT: Fragment-based drug design exploits initial screening of low molecular weight compounds and their concomitant affinity improvement. The multitude of possible chemical modifications highlights the necessity to obtain structural information about the binding mode of a fragment. Herein we describe a novel NMR methodology (LOGSY titration) that allows the determination of binding modes of low affinity binders in the protein-ligand interface and reveals suitable ligand positions for the addition of functional groups that either address or substitute protein-bound water, information of utmost importance for drug design. The particular benefit of the methodology and in contrast to conventional ligand-based methods is the independence of the molecular weight of the protein under study. The validity of the novel approach is demonstrated on two ligands interacting with bromodomain 1 of bromodomain containing protein 4, a prominent cancer target in pharmaceutical industry.

\section{INTRODUCTION}

Rational drug design is an iterative process, in which $3 \mathrm{D}$ structural information about a specific protein-ligand interaction is used to generate an inhibitor that specifically blocks a targeted interaction. NMR spectroscopy provides well-established methods for initial library screening, as saturation transfer difference (STD), ${ }^{1,2}$ water ligand observed via gradient spectroscopy (WaterLOGSY), ${ }^{3,4}$ fluorine NMR ( ${ }^{19} \mathrm{~F}$ NMR $),{ }^{5}$ structure-activity relationship by NMR (SAR by NMR). ${ }^{6}$ Additionally, NMR methods were developed that allow the characterization of the ligand orientation in the protein-bound state, e.g., adiabatic fast passage nuclear Overhauser effect spectroscopy (AFP-NOESY), ${ }^{7}$ interligand NOE (ILOE) for pharmacophore mapping (INPHARMA), ${ }^{8}$ solvent accessibility, ligand binding, and mapping of ligand orientation by NMR (SALMON), ${ }^{9}$ group epitope mapping (GEM) by STD, ${ }^{1}$ difference of inversion recovery rate with and without target irradiation (DIRECTION), ${ }^{10}$ transferred nuclear Overhauser effect (NOE) spectroscopy. ${ }^{11,12}$ Since X-ray cocrystallographic structure determination of protein-ligand complexes of initial hits is sometimes not feasible, independent techniques are required that provide specific information about ligand epitopes, as well as the protein surroundings of the bound ligand, to aid the systematic optimization of compounds. Especially, knowledge of ligand positions that are close to protein-bound water molecules will be very valuable for the choice of chemical modification to be introduced at certain ligand positions.

In our study we employ GEM by $\mathrm{STD}^{1}$ and a novel application of the WaterLOGSY ${ }^{4}$ method called LOGSY titration to distinguish between buried and solvent-accessible parts of ligands, as well as to map protein-bound water molecules that are in proximity to the ligand. As published, WaterLOGSY 4 experiments also allow the extraction of information about solvent-accessible epitopes of a ligand. The SALMON approach uses the sign of a WaterLOGSY cross peak in the spectrum of the ligand in the presence of the protein as a measure of solvent accessibility. ${ }^{2,9}$ Negative cross peaks are observed only for highly solvent exposed ligand protons, whereas positive cross peaks stem from buried ligand protons. We noticed that for weakly binding ligands, especially in combination with small proteins, positive WaterLOGSY cross peaks are hardly observed, which hampers the extraction of differential solvent accessibility scores with the SALMON methodology. Therefore, we propose performing WaterLOGSY experiments at increasing protein concentrations and using the titration slopes as a measure of solvent accessibility. A major advantage of the LOGSY-titration method is its applicability to small proteins, as it probes the influence of the protein on the solvation of the ligand. The potential of this new methodology

Received: June 21, 2017

Published: September 14, 2017 


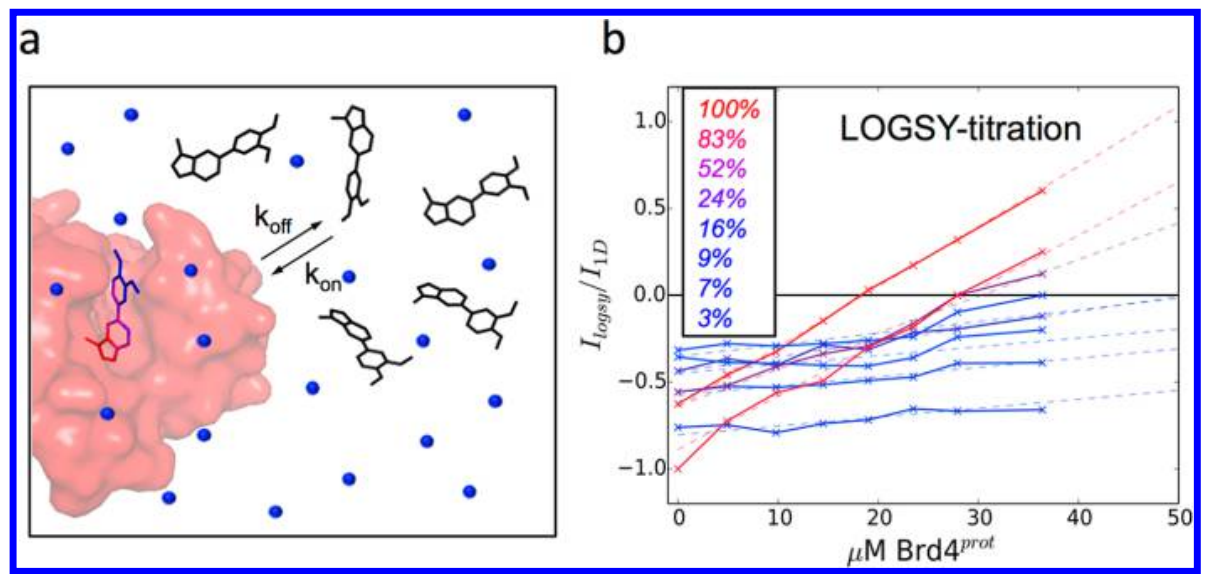

Figure 1. Concept of the LOGSY-titration experiment. (a) For reversibly binding ligands ( $\mathrm{mM}$ to $\mu \mathrm{M}$ ) magnetization received from water during the WaterLOGSY experiment is a combination of cross-relaxation obtained from bulk water and cross-relaxation transferred either directly via protein-bound water molecules or indirectly via spin-diffusion mediated by protein protons. (b) LOGSY-titration: $I_{\text {logsy }} / I_{\text {ref }}$ is plotted as a function of the protein concentration. Intensities in the WaterLOGSY are normalized to the ${ }^{1} \mathrm{H} 1 \mathrm{D}$ reference spectrum measured at the same protein concentration. The slopes are fitted to a linear function and normalized to the graph with the strongest slope (LOGSY factor of $100 \%)$.

is illustrated with an application to the bromodomain 1 of bromodomain containing protein 4 (Brd4-BD1). ${ }^{13} \operatorname{Brd} 4$ is a member of the bromodomain and extra-terminal (BET) family that contains two tandem bromodomains (BD1 and BD2) and binds to acetylated lysines in histones. ${ }^{13,14}$ Inhibition of Brd4chromatin interaction is relevant for the treatment of various forms of cancer and has been shown to have potent antiproliferative effects in a variety of hematological cancers through the suppression of c-MYC and FOSL1 transcription. $^{8,15-17}$

We successfully could map buried and solvent-accessible epitopes in two ligands interacting with Brd4-BD1, revealing an unexpected flip of a core aromatic scaffold shared by the two ligands. Furthermore, we predicted ligand positions, which are in proximity to protein-bound water. Concomitant introduction of a secondary amine at a suggested position led to significant improvement of affinity of ligands by replacing weakly interacting $\mathrm{H}_{2} \mathrm{O}$ and forming a hydrogen bond to a nearby asparagine residue.

\section{RESULTS}

Determination of Ligand Binding Modes with LOGSY Titrations. Figure 1 illustrates the LOGSY-titration experiment. For a reversibly binding ligand the magnetization transferred by cross-relaxation from irradiated or selectively inverted water to ligand protons is a population weighted average of free (positive) and bound (negative) cross-relaxation contributions (Figure 1a). Increasing the amount of protein will shift the equilibrium toward the protein-bound state and eventually lead to a sign change of the observed cross peaks. The amount of bound cross-relaxation received via the protein depends on the peculiarities of the binding pocket (nearby bound water molecules, proton density at the interaction site) as well as the kinetics of the protein-ligand interaction. As individual ligand protons will experience a different surrounding in the protein-bound state, cross peaks of different ligand protons will behave differently during the LOGSY-titration (Figure 1b).

We used mixing times of $\tau_{\text {mix }}=1 \mathrm{~s}$ for the WaterLOGSY experiments, where the cross peak intensities for our ligands have their maximum. Increased amounts of protein will lead to an increase in macromolecular cross-relaxation from water to the ligand, either directly via protein-bound water molecules or indirectly via spin-diffusion mediated by protein protons. Ligand protons that are close to the protein in the bound state will show stronger LOGSY-titration slopes than ligand protons that are solvent-accessible in the bound state and not in close contact with the protein. The fitted slopes are normalized to the signal with the strongest slope (100\% LOGSY factor) (Figure 1b). Figure S2 in the Supporting Information provides simulations of expected LOGSY-titration cross peak intensities, demonstrating that at low protein concentrations the intensity changes approximately linearly with protein concentration.

Typically, values around $100 \%$ correspond to ligand protons that receive a maximum of magnetization via the protein or protein-bound water molecules, whereas values smaller than $20 \%$ delineate protons that are facing the solvent in the bound state. Intermediate values correspond to protons positioned between protein and solvent. Importantly, since only the slope of the titration curve is analyzed, relevant information can be obtained also in cases where no zero crossing occurs (for example, in the case of weak binders in combination with low molecular weight proteins, as well as ligand signals for highly solvent-accessible protons). This feature is particularly attractive given that in early stages of the drug design process ligands tend to have moderate affinities.

Figure 2 shows LOGSY-titration factors and STD amplification factors $\left(\mathrm{STD}-\mathrm{AF}_{0}\right)$ of two ligands $\mathbf{1}$ and 2, which reversibly bind to Brd4-BD1 with $\mathrm{IC}_{50}(1)=24 \mu \mathrm{M}$, and $\mathrm{IC}_{50}(2)=2 \mu \mathrm{M}$, respectively. X-ray cocrystal structures of both ligands were available and could be compared to the NMR derived LOGSY and STD enhancements. In both ligands, protons of the triazolopyridazine moiety have the largest LOGSY and STD-AF $F_{0}$ values, showing that this part of the ligand is deeply embedded in the protein-binding site. The different substituents, for example, the methoxy groups 2 and 3 and aromatic protons of the phenyl moiety in ligand $\mathbf{1}$, as well as aromatic protons of the phenyl group in ligand 2, display smaller LOGSY and STD-AF ${ }_{0}$ values, respectively.

Still, while the distribution of STD values is nearly the same for both ligands, LOGSY factors reveal significant differences for both ligands and thereby indicate different ligand binding modes. Most important, while the STD-AF $\mathrm{F}_{0}$ values of the methyl group 1 of the two ligands are similar (99\% and 100\%), 


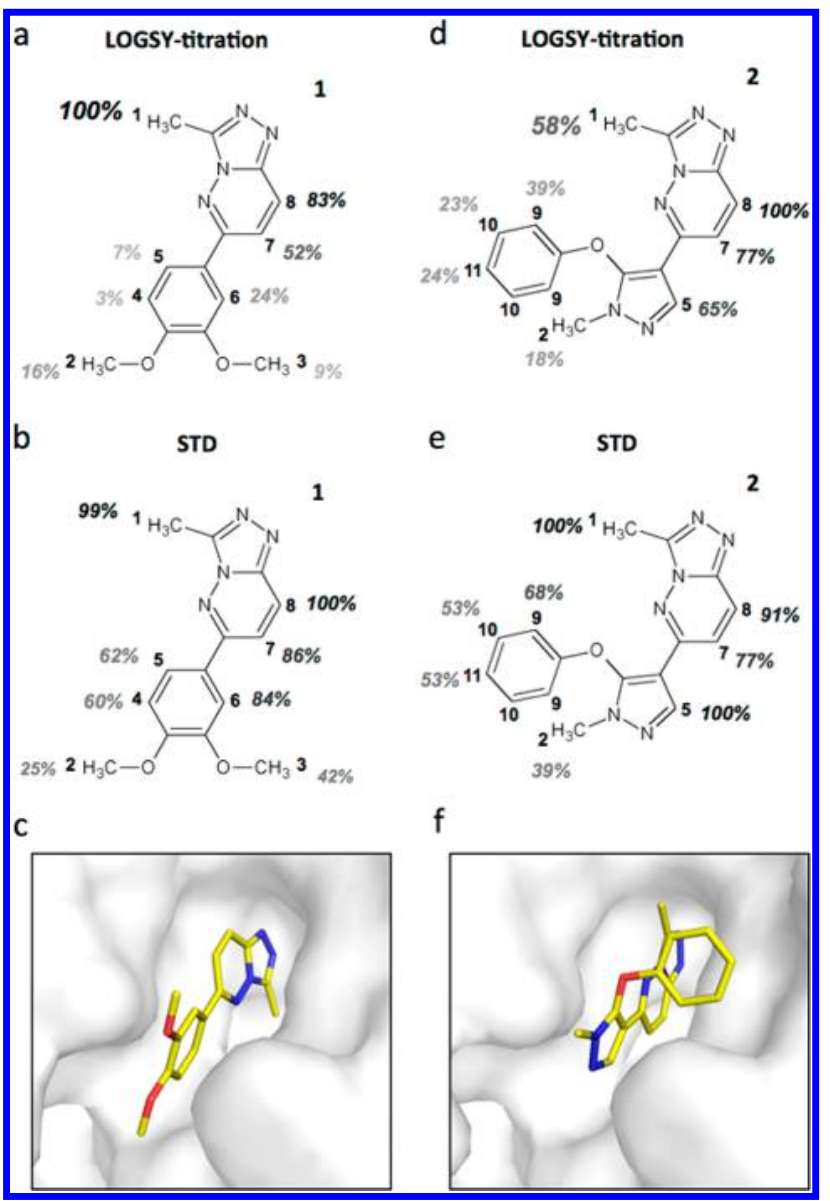

Figure 2. LOGSY factors calculated from the slopes of the LOGSY titrations and normalized STD-AF $F_{0}$ values for $(\mathrm{a}, \mathrm{b})$ ligand $\mathbf{1}$ and $(\mathrm{d}, \mathrm{e})$ ligand 2. (c, f) X-ray cocrystal structures of the complexes Brd4-BD1 with ligand 1 (5M39) and ligand 2 (5M3A), respectively.

they have a significantly different LOGSY factor. In ligand $\mathbf{2}$ it is clearly reduced (58\% compared to $100 \%$ ) and is indicative of a different hydration shell located around the position of the methyl group (compare Figure $2 \mathrm{a}$ and Figure 2d). The binding mode of the triazolopyridazine moiety is indeed flipped, as confirmed in the X-ray structure, leading to a higher solvent accessibility for this methyl group in ligand $\mathbf{2}$ as shown in Figure 2f. This flip would not have been predicted from the STD-NMR spectra, most likely due to the fact that the protein environment with regard to the nonexchangeable protons is similar in the two binding modes leading to similar STD enhancements. The NMR results are therefore in excellent general agreement with the position of the ligand in the binding pocket obtained from the X-ray crystal structure.

In sum, both STD-NMR and LOGSY titrations provide information about ligand binding epitopes; however only the LOGSY factors revealed the flipped binding mode of the triazolopyridazine ring system of ligand 2 . It can thus be concluded that in medicinal chemistry applications STD data are valuable for the identification of ligand positions in close proximity to the protein-binding interface, whereas additional information about their hydration shells can be obtained using the LOGSY-titration technique.

Determination of Protein-Bound Water in Proximity to Ligand Protons. It has to be noted that in the LOGSY experiment the NOESY transfer between ligand and protein also involves spin-diffusion via protein protons in the binding cleft. We therefore performed LOGSY titrations with perdeuterated protein to suppress spin-diffusion via the protein in order to detect direct NOEs from protein-bound water molecules to the ligand (Figure 3a and Figure 3c). Accordingly,

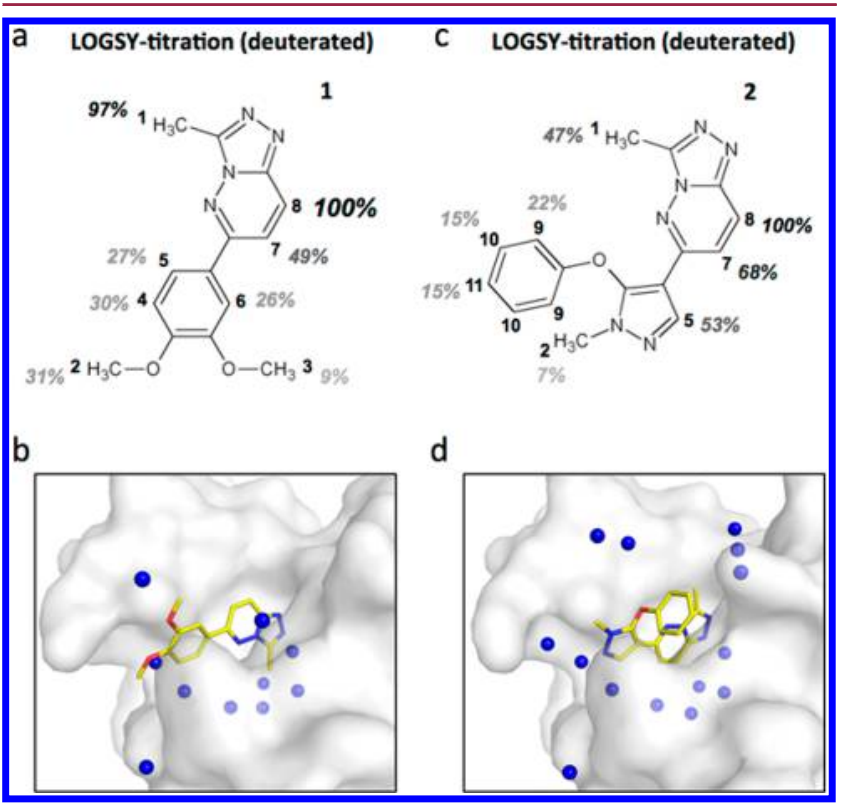

Figure 3. LOGSY factors calculated from the slopes of the LOGSY titrations with perdeuterated Brd4-BD1 for (a) ligand 1 and (c) ligand 2. $100 \%$ corresponds to the signal with the strongest slope. (b, d) Xray cocrystal structures of the complexes Brd4-BD1 with ligand 1 (5M39) and ligand 2 (5M3A), respectively. $\mathrm{H}_{2} \mathrm{O}$ molecules resolved in the electron density map and within a distance of $6 \AA$ from the ligand are shown as blue spheres.

large LOGSY factors are found for protons exhibiting NOEs to interfacial water molecules (embedded in the interaction interface), while ligand protons accessible to solvent water molecules display smaller values. Maximal LOGSY factors were found for protons experiencing cross-relaxation to ordered water molecules located at the bottom of the binding cleft (Figure $3 \mathrm{~b}$ and Figure 3d). Specifically, strong (direct) water NOEs were observed for methyl-group 1 of ligand 1 and (due to the swapped orientation of the triazolopyridazine ring) to the aromatic proton 8 of ligand 2. Most interestingly, however, a significant water NOE was found for aromatic proton 8 of ligand $\mathbf{1}$ (Figure $3 \mathrm{~b}$ ).

It is instructive to compare our findings with available $\mathrm{X}$-ray data from other ligand-Brd4 complexes available in-house. In total, 11 complex structures were examined in which the ligands do not contain functional groups corresponding to the position 8 , which would interfere with potential protein-bound water at that site. In all 11 crystal structures highly ordered water molecules were found in conserved positions of the binding pocket of Brd4-BD1 and close to methyl group 1 of ligand 1 (Figure 4, blue spheres). The interaction interface contains a second water cluster although with higher positional variability (Figure 4, yellow spheres) as well as water molecules in an exposed cluster (Figure 4, red spheres), which were detectable in only 6 out of 11 complex structures, suggesting that water molecules in this part of the hydration shell are less ordered and presumably part of a dynamic water cluster. Water molecules located in this cluster are presumably responsible for the observed water NOE to the aromatic proton at position 8 of 


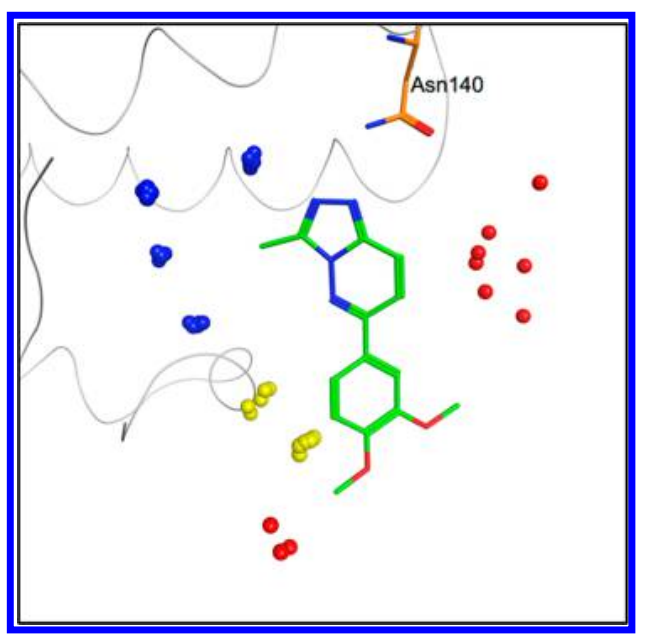

Figure 4. Superposition of $\mathrm{H}_{2} \mathrm{O}$ molecules in Brd4-BD1 complex structures of six different ligand cocrystal structures. Ligand $\mathbf{1}$ is shown as representative ligand structure. Spheres represent $\mathrm{H}_{2} \mathrm{O}$ molecules found in the X-ray structures of the complexes (blue, highly ordered, and consistently found in all complexes; yellow, low positional variation; red, large positional variation and not conserved in all protein-ligand complexes).

ligand 1. Here it should be noted that there is ample evidence that X-ray protein crystallography does not reliably detect loosely defined hydration water molecules. ${ }^{18}$ In contrast, it is well established that NMR also identifies transiently bound or "disordered" water molecules that are not always resolved in the electron density map. ${ }^{19}$ Our findings nicely demonstrate that the LOGSY-titration experiment reported here is a powerful and efficient technique to probe the existence and location of transiently bound water molecules in protein ligand complexes. These water molecules could be valid starting points for chemical replacement strategies to displace or substitute bound water molecules by suitable functional groups.

We thus suggest exploiting the experiment with perdeuterated protein for the identification of protons with large LOGSY factors as the primary candidates for substitution with groups that either displace or address protein-bound water molecules. Successful applications for this novel strategy are shown in the Supporting Information (Table S1). Overall, the replacement of the aromatic proton 8 with an amino or aminomethyl group in a series of ligands containing the triazolopyridazine ring led up to a 100 -fold increase in binding affinity (Table S1). Consistently, in all X-ray cocrystal structures obtained with such a modification, the triazolopyridazine ring binding mode of ligand $\mathbf{1}$ was found (methyl group pointing inward), and the (substituted) amino group was found to be hydrogen-bonded to the side chain of Asn140 of Brd4BD1.

\section{DISCUSSION AND CONCLUSIONS}

Detailed information about the binding mode of a fragment to its target as well as its environment in the bound state is indispensable for medicinal chemists to optimize early phase lead candidates with respect to affinity and specificity. Although $\mathrm{X}$-ray crystallography is the method of choice to provide highresolution structural information, it often fails in early stages of the drug optimization process because of low binding affinity and concomitantly compromised protein crystallizability. Additionally, it is well established that water molecules are often found at the protein-ligand interaction interface and contribute to the binding affinity by forming distinct hydrogen bonding patterns. Despite their crucial role in ligand-binding events, they are sometimes undetectable by X-ray crystallography. To overcome this bottleneck, we present a novel ligandbased NMR spectroscopy approach for the probing of ligand binding modes and the characterization of water hydration shells in protein-ligand binding clefts.

Although our methodology shares some similarities with the already mentioned SALMON approach using short mixing times $\left(\tau_{\text {mix }}=150 \mathrm{~ms}\right)$, it is important to stress the fundamental differences. ${ }^{2}$ The use of short mixing times was shown to be necessary for the extraction of solvent-accessible epitopes of very buried ligands. ${ }^{2}$ Unfortunately, due to the small size of Brd4-BD1 ( $\mathrm{MW}=15 \mathrm{kDa}$ ), it was impossible to record positive WaterLOGSY cross peaks for any of the ligands. Switching back to longer mixing times $\left(\tau_{\text {mix }}=1 \mathrm{~s}\right)$, we realized that the distribution of positive and negative cross peaks strongly depends on the affinity of the ligand and on the protein concentration.

Figure 5a shows the 1D spectrum and two WaterLOGSY spectra of ligand $\mathbf{2}$ recorded at two different protein

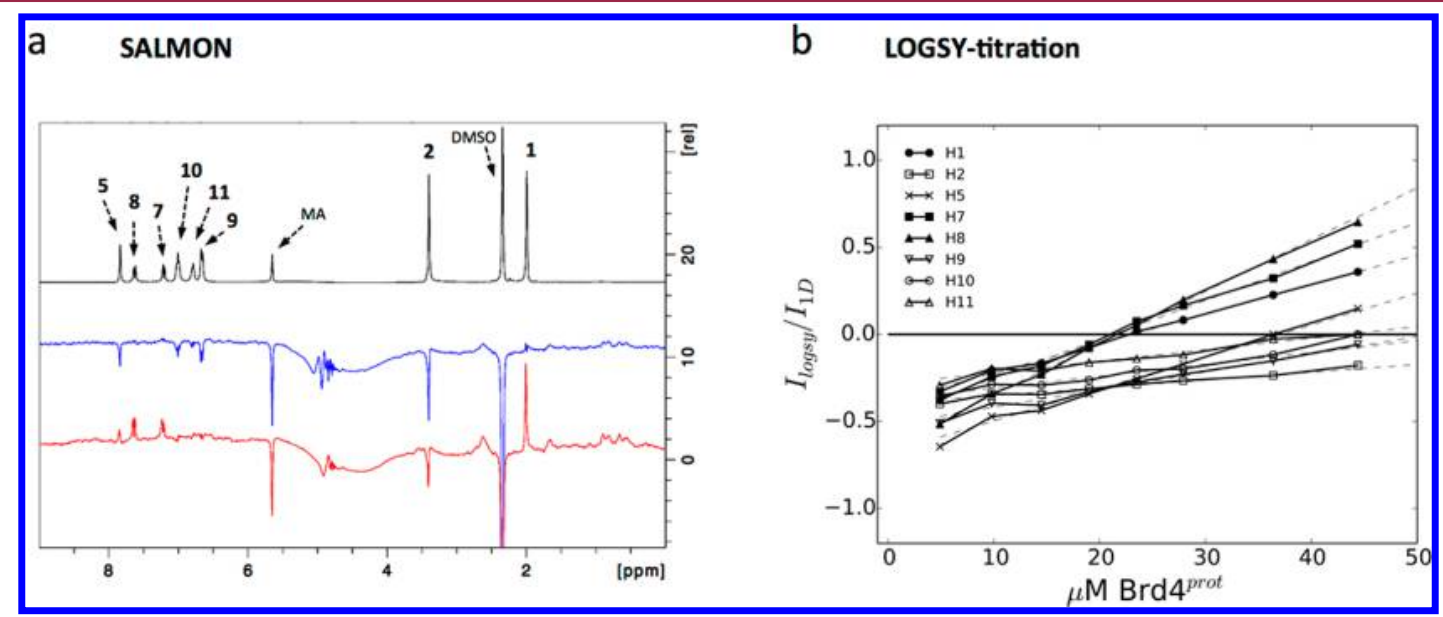

Figure 5. Comparison between SALMON and LOGSY titration of ligand 2 interacting with protonated Brd4-BD1: (a) 1D spectrum of ligand 2 (1 $\mathrm{mM}$ ) and WaterLOGSY spectra of ligand 2 with $24 \mu \mathrm{M}$ Brd4-BD1 (blue) and $45 \mu \mathrm{M}$ Brd4-BD1 (red); (b) LOGSY-titration of ligand 2 interacting with Brd4-BD1 (5-45 $\mu \mathrm{M})$. 
Table 1. Chromatography Methods

\begin{tabular}{|c|c|c|c|c|c|}
\hline & column $^{a}$ & solvent A & solvent B & $\begin{array}{l}\text { flow rate } \\
(\mathrm{mL} / \mathrm{min})\end{array}$ & gradient $^{b}$ \\
\hline A1 & Aquity UPLC BEH, C18, $1.7 \mu \mathrm{m}, 2,1 \mathrm{~mm} \times 100 \mathrm{~mm}, 40{ }^{\circ} \mathrm{C}$ & water with $0.1 \%$ formic acid & $\begin{array}{l}\text { acetonitrile with } \\
0.1 \% \text { formic } \\
\text { acid }\end{array}$ & 0.4 & $05 \% \rightarrow 100 \%, 7 \mathrm{~min}$ \\
\hline $\mathrm{A} 2$ & Venusil XBP-C18, $5 \mu \mathrm{m}, 2.1 \mathrm{~mm} \times 50 \mathrm{~mm}, 50{ }^{\circ} \mathrm{C}$ & water with $0.04 \%$ TFA & $\begin{array}{l}\text { acetonitrile with } \\
0.02 \% \text { TFA }\end{array}$ & 1.0 & $10 \% \rightarrow 80 \%, 3 \mathrm{~min}$ \\
\hline $\mathrm{A} 3$ & Waters XBridge, C18, $2.5 \mu \mathrm{m}, 2.1 \mathrm{~mm} \times 20 \mathrm{~mm}, 60^{\circ} \mathrm{C}$ & water, pH $9.2\left(20 \mathrm{mM} \mathrm{NH} \mathrm{HCO}_{3}\right)$ & acetonitrile & 1.0 & $10 \% \rightarrow 95 \%, 1.5 \mathrm{~min}$ \\
\hline P1_a & Waters XBridge, $\mathrm{C} 18,10 \mu \mathrm{m}, 30 \mathrm{~mm} \times 100 \mathrm{~mm}$ & water, $\mathrm{pH} 8$ (buffer: $\mathrm{NH}_{3}, \mathrm{NH}_{4} \mathrm{HCO}_{3}$ ) & acetonitrile & 100 & $05 \% \rightarrow 60 \%, 6 \min$ \\
\hline P1_b & Waters XBridge, C18, $10 \mu \mathrm{m}, 50 \mathrm{~mm} \times 100 \mathrm{~mm}$ & water, pH 8 (buffer: $\mathrm{NH}_{3}, \mathrm{NH}_{4} \mathrm{HCO}_{3}$ ) & acetonitrile & 100 & $05 \% \rightarrow 95 \%, 12 \mathrm{~min}$ \\
\hline $\mathrm{P} 2$ & Waters Sunfire, C18, $10 \mu \mathrm{m}, 63 \mathrm{~mm} \times 100 \mathrm{~mm}$ & water with $0.2 \%$ formic acid & acetonitrile & 100 & $02 \% \rightarrow 30 \%, 6 \mathrm{~min}$ \\
\hline
\end{tabular}

concentrations (24 $\mu \mathrm{M}$ Brd4-BD1 in blue, $45 \mu \mathrm{M}$ Brd4-BD1 in red). It is important to note that the distribution of positive and negative signals is fairly different depending on the protein concentration. As can be seen from Figure 5a, although the SALMON approach provides a rough assessment of the ligand binding epitope, further details cannot be concluded from a single point measurement. In contrast, Figure $5 b$ clearly shows that analysis of the corresponding LOGSY-titration curves reveals far more details about the ligand binding mode and internally bound water molecules. Most importantly, we could demonstrate that the method also identifies transiently bound or "disordered" water molecules that are not always resolved in the electron density map and that these water molecules are valid starting points for chemical replacement strategies to substitute bound water molecules by suitable functional groups. Several studies have shown that hydration water plays a pivotal role not only for the folding of proteins but also for proteinligand interaction. ${ }^{20}$ An example of the beneficial impact of replacing water molecules to binding affinities was provided by Grzesiek and co-workers, who could show that a carbonyl group of the high-affinity HIV protease inhibitor DMP323 replaces a conserved $\mathrm{H}_{2} \mathrm{O}$ molecule and thereby contributes to the total binding free energy. ${ }^{21}$ The possibility of identifying protein-bound water molecules close to the bound ligand will clearly be of great value for the decision of medicinal chemists to incorporate additional functional groups, which either address retainable water or replace substitutable water. It is important to note that this valuable information is provided without atomistic structural information commonly provided by X-ray crystallography.

In summary, we present a novel NMR approach for probing solvent accessibility and ligand binding modes of proteinligand complexes. Most importantly, the method allows the identification of ligand positions for medicinal chemistry modifications to improve binding affinities through substituting or addressing bound water molecules. Given the facile applicability of the approach and the advantage of not needing a complete structure of the protein or a protein-ligand complex, we anticipate wide usage of the method particularly at early stages of drug discovery and especially for targets where obtaining X-ray cocrystal structures is limited or not possible.

\section{EXPERIMENTAL SECTION}

Synthetic Methods. General Remarks. Chemicals and reagents were obtained from commercial suppliers and were used without further purification. Proton and carbon NMR spectra were obtained on a Bruker Avance 400 FT-NMR or Bruker Avance 500 FT-NMR instrument with chemical shifts $(\delta)$ reported relative to tetramethylsilane as an internal standard. High resolution mass spectrometry data were obtained on a LTQ Orbitrap XL (Thermo Scientific) equipped with a NSI source (Advion Nanomate) in ESI positive mode. Analytical HPLC-MS analyses were conducted using an Agilent $1100 / 1200$ series LC/MSD system or UPLC-micromass triple quad. The analytic methods A1, A2, and A3 are defined in Table 1 . Compound purities were calculated as the percentage peak area of the analyzed compound by UV detection at $230-400 \mathrm{~nm}$. If purity data are not explicitly mentioned, the compound displays a purity of $>95 \%$. Flash column chromatography was carried out using hand packed silica gel 60 (100-200 mesh), and product was eluted under medium pressure liquid chromatography. Preparative high performance chromatography was carried out on a Gilson system (pump system, 333 and 334 prep-scale HPLC pump; fraction collector, 215 liquid handler; detector, Gilson UV/vis 155) using prepacked reversed phase silica gel columns from Waters. The methods for preparative high performance chromatography P1_a, P1_b, and P2 are defined in Table 1.

Selected Experimental Procedures. Synthesis of Ligand 1. Scheme S1 in the Supporting Information shows the structures of the compounds involved in the synthesis of ligand 1.

6-(3,4-Dimethoxyphenyl)-3-methyl[1,2,4]triazolo[4,3-b]pyridazine (1). 6-Chloro-3-methyl[1,2,4] triazolo[4,3-b]pyridazine $(30 \mathrm{mg}, 0.178 \mathrm{mmol}), 3$,4-dimethoxyphenylboronic acid $(35 \mathrm{mg}$, $0.19 \mathrm{mmol}$ ), cesium carbonate (139 $\mathrm{mg}, 0.43 \mathrm{mmol}$ ), and $1,1^{\prime}$ (bis(diphenylphosphino)ferrocenepalladium(II) dichloride, dichloromethane $(15 \mathrm{mg}, 0.02 \mathrm{mmol})$ were dissolved in $0.2 \mathrm{~mL}$ of THF. The mixture was stirred for $30 \mathrm{~min}$ at $100{ }^{\circ} \mathrm{C}$. The crude product was purified using method P1_a, yielding $0.04 \mathrm{~g}(38 \%, 0.12 \mathrm{mmol})$ of the title compound. Purity by method A3: $>95 \%, t_{\mathrm{R}}=0.82 \mathrm{~min}$. MS $\left(\mathrm{ESI}^{+}\right) \quad m / z 271(\mathrm{M}+\mathrm{H})^{+}$. HRMS $(\mathrm{m} / z):[\mathrm{M}]^{+}$calcd for $\mathrm{C}_{14} \mathrm{H}_{14} \mathrm{~N}_{4} \mathrm{O}_{2}, 270.1117$; found, 270.1111. ${ }^{1} \mathrm{H}$ NMR (DMSO- $d_{6}, 500$ $\mathrm{MHz}): \delta=8.46(\mathrm{~d}, J=9.8 \mathrm{~Hz}, 1 \mathrm{H}), 8.16(\mathrm{~d}, J=9.8 \mathrm{~Hz}, 1 \mathrm{H}), 7.78(\mathrm{dd}$ $J=8.5,2.2 \mathrm{~Hz}, 1 \mathrm{H}), 7.72(\mathrm{~d}, J=2.2 \mathrm{~Hz}, 1 \mathrm{H}), 7.16(\mathrm{~d}, J=8.5 \mathrm{~Hz}, 1 \mathrm{H})$, $3.90(\mathrm{~s}, 3 \mathrm{H}), 3.86(\mathrm{~s}, 3 \mathrm{H}), 2.82 \mathrm{ppm}(\mathrm{s}, 3 \mathrm{H}) .{ }^{13} \mathrm{C}$ NMR (DMSO-d $125 \mathrm{MHz}): \delta=153.3,151.5,149.1,146.7,142.2,125.8,123.8,121.4$, 120.9, 111.8, 110.1, 55.7, 55.6, $9.2 \mathrm{ppm}$.

Synthesis of Ligand 2. Scheme S2 in the Supporting Information shows the structures of the compounds involved in the synthesis of ligand 2.

1-Methyl-5-phenoxy-1H-pyrazole-4-carboxylic Acid Ethyl Ester (2). Phenol (18.17 g; $193.08 \mathrm{mmol}$ ) was dissolved in $500 \mathrm{~mL}$ of DMA. Potassium carbonate (53.37 g; $386.16 \mathrm{mmol}$ ) was added in small portions, and the mixture was stirred for $10 \mathrm{~min}$ at room temperature. Afterward 5-bromo-1-methyl-1H-pyrazole-4-carboxylic acid ethyl ester $(30.00 \mathrm{~g} ; 128.72 \mathrm{mmol})$ was added to the reaction mixture dropwise and stirred for $16 \mathrm{~h}$ at $140{ }^{\circ} \mathrm{C} .10 \%$ citric acid solution and dichloromethane were added. The organic layer was separated, dried, and the solvent was removed under reduced pressure. The crude product was purified using silica gel flash column chromatography with a solvent mixture of ethyl acetate and hexane for elution. The solvent of the corresponding fractions was evaporated under reduced pressure, yielding $18 \mathrm{~g}(57 \%, 73.0 \mathrm{mmol})$ of the title compound. Purity by method A2: $>95 \% ; t_{\mathrm{R}}=1.07 \mathrm{~min}$. MS $\left(\mathrm{ESI}^{+}\right) \mathrm{m} /$ $z 247(\mathrm{M}+\mathrm{H})^{+} .{ }^{1} \mathrm{H}$ NMR $\left(400 \mathrm{MHz}, \mathrm{CDCl}_{3}\right) \delta(\mathrm{ppm}) 7.92(\mathrm{~s}, 1 \mathrm{H})$, 
$7.28-7.22(\mathrm{~m}, 2 \mathrm{H}), 7.14-7.05(\mathrm{~m}, 1 \mathrm{H}), 6.92-6.86(\mathrm{~d}, 2 \mathrm{H}), 4.15-$ $4.02(\mathrm{~m}, 2 \mathrm{H}), 3.71(\mathrm{~s}, 3 \mathrm{H}), 1.02-1.10(\mathrm{~m}, 3 \mathrm{H})$.

1-Methyl-5-phenoxy-1H-pyrazole-4-carboxylic Acid (3). 1Methyl-5-phenoxy-1H-pyrazole-4-carboxylic acid ethyl ester 3 (0.45 g; $1.83 \mathrm{mmol}$ ) was dissolved in $10 \mathrm{~mL}$ of a 1:1 mixture of methanol and THF. Lithium hydroxide $(0.15 \mathrm{~g} ; 3.66 \mathrm{mmol})$ in $5 \mathrm{~mL}$ of water was added, and the reaction mixture was stirred for $16 \mathrm{~h}$ at $20{ }^{\circ} \mathrm{C}$. Ethyl acetate was added to the mixture, and the aqueous layer was acidified with $1 \mathrm{M}$ aqueous hydrochloric acid. The organic layer was removed under reduced pressure. The crude product yields $0.25 \mathrm{~g}(63 \%, 1.15$ $\mathrm{mmol})$ of the title compound. Purity by method A1: $>95 \% ; t_{\mathrm{R}}=2.92$ min. MS $\left(\mathrm{ESI}^{+}\right) \mathrm{m} / z 219(\mathrm{M}+\mathrm{H})^{+} .{ }^{1} \mathrm{H}$ NMR $\left(400 \mathrm{MHz}, \mathrm{CDCl}_{3}\right) \delta$ (ppm) 9.80-12.20 (br, 1H), 7.92 (s, 1H), 7.34-7.22 (m, 2H), 7.12 (m, 1H), 6.92-6.85 (m, 2H), $2.65(\mathrm{~s}, 3 \mathrm{H})$.

4-lodo-1-methyl-5-phenoxy-1 H-pyrazole (5). Under an atmosphere of argon, 1-methyl-5-phenoxy-1H-pyrazole-4-carboxylic acid 4 (20.00 g; $91.66 \mathrm{mmol}$ ) was suspended in $6.40 \mathrm{~mL}$ of tert-butanol and $160 \mathrm{~mL}$ of 1,4-dioxane. DIPEA (45.56 mL; $274.97 \mathrm{mmol}$ ) and diphenyl phosphorazidate $(52.97 \mathrm{~g} ; 192.48 \mathrm{mmol})$ were added to the mixture and stirred for $10 \mathrm{~min}$ at $20^{\circ} \mathrm{C}$. Afterward the mixture was stirred for $3 \mathrm{~h}$ at $110{ }^{\circ} \mathrm{C}$. The solvent was removed under reduced pressure. The residue was purified using silica gel flash column chromatography with a solvent mixture of ethyl acetate and hexane for elution. The solvent of the corresponding fractions was evaporated under reduced pressure. This intermediate was dissolved in $4 \mathrm{M}$ hydrochloric acid in 1,4-dioxane $(3.20 \mathrm{~mL} ; 12.80 \mathrm{mmol})$ and stirred for 2 days at $20^{\circ} \mathrm{C}$. The solvent was removed under reduced pressure. Aqueous sodium hydrogen carbonate solution and ethyl acetate were added to the residue. The organic layer was separated, dried, and the solvent was removed under reduced pressure. The crude product 1methyl-5-phenoxy-1H-pyrazol-4-ylamine 5 (4 g, $21.0 \mathrm{mmol}$, 23\%) was dissolved in aqueous hydrochloric acid $(162 \mathrm{~mL} ; 648 \mathrm{mmol})$ and cooled down to $0{ }^{\circ} \mathrm{C}$. Afterward sodium nitrite $(1.9 \mathrm{~g} ; 2.7 \mathrm{mmol})$ dissolved in water was added and the mixture was stirred for $1 \mathrm{~h}$ at 0 ${ }^{\circ} \mathrm{C}$. Then potassium iodide $(10.5 \mathrm{~g} ; 63 \mathrm{mmol})$ was added with vigorous stirring, and within $30 \mathrm{~min}$ the mixture warmed to $20^{\circ} \mathrm{C}$. An amount of $2 \mathrm{~mL}$ of water was added to the reaction mixture and neutralized with aqueous sodium hydrogen carbonate solution. Dichloromethane was added, the organic layer was separated and dried, and the solvent was removed under reduced pressure. The crude product was purified using silica gel flash column chromatography with a solvent mixture of ethyl acetate and petroleum ether for elution. The solvent of the corresponding fractions was evaporated under reduced pressure, yielding $3.8 \mathrm{~g}(61 \% ; 12.7 \mathrm{mmol})$ of the title compound. Purity by method A2: $>95 \% ; t_{\mathrm{R}}=1.93 \mathrm{~min}$. MS $\left(\mathrm{ESI}^{+}\right) \mathrm{m} / z 301(\mathrm{M}+$ $\mathrm{H})^{+} .{ }^{1} \mathrm{H}$ NMR $\left(400 \mathrm{MHz}, \mathrm{CDCl}_{3}\right) \delta(\mathrm{ppm}) 7.46(\mathrm{~s}, 1 \mathrm{H}), 7.34-7.30$ (m, 2H), $7.10(\mathrm{~m}, 1 \mathrm{H}), 6.89-6.87(\mathrm{~m}, 2 \mathrm{H}), 3.69(\mathrm{~s}, 3 \mathrm{H})$.

(1-Methyl-5-phenoxy-1H-pyrazol-4-yl)boronic Acid (6). 4Iodo-1-methyl-5-phenoxypyrazole $6(0.5 \mathrm{~g} ; 1.67 \mathrm{mmol})$ was dissolved in THF and cooled down at $-70{ }^{\circ} \mathrm{C}$. Afterward triisopropyl borate (0.35 g; $1.83 \mathrm{mmol}$ ) and $2.5 \mathrm{M} n$-butyllithium (1.06 mL; $2.67 \mathrm{mmol})$ were added to the solution and warmed overnight to $20^{\circ} \mathrm{C}$. The crude product was purified using silica gel flash column chromatography with a solvent mixture of ethyl acetate and petroleum ether for elution. The solvent of the corresponding fractions was evaporated under reduced pressure, yielding $0.15(41 \%, 0.69 \mathrm{mmol})$ of the title compound. Purity by method A2 > 95\%; $t_{\mathrm{R}}=2.84 \mathrm{~min}$. MS $\left(\mathrm{ESI}^{+}\right) \mathrm{m} / z 219(\mathrm{M}+\mathrm{H})^{+}$. ${ }^{1} \mathrm{H}$ NMR (400 MHz, $\left.\mathrm{CDCl}_{3}\right) \delta(\mathrm{ppm}) 7.67(\mathrm{~s}, 1 \mathrm{H}), 7.38-7.34(\mathrm{~m}$, $2 \mathrm{H}), 7.12(\mathrm{~m}, 1 \mathrm{H}), 6.93-6.91(\mathrm{~m}, 2 \mathrm{H}), 3.67(\mathrm{~s}, 3 \mathrm{H})$.

3-Methyl-6-(1-methyl-5-phenoxy-1 H-pyrazol-4-yl) $[1,2,4]-$ triazolo[4,3-b]pyridazine (7). 6-Chloro-3-methyl[1,2,4] triazolo[4,3b]pyridazine (70.00 mg; $0.42 \mathrm{mmol}$ ), (1-methyl-5-phenoxy-1Hpyrazol-4-yl)boronic acid (99.58 $\mathrm{mg} ; 0.46 \mathrm{mmol})$, and sodium carbonate $(88.02 \mathrm{mg} ; 0.83 \mathrm{mmol})$ were suspended in water $(0.35$ $\mathrm{mL} ; 19.12 \mathrm{mmol})$ and $\mathrm{N}, \mathrm{N}$-dimethylformamide $(4.00 \mathrm{~mL} ; 51.98$ mmol). The reaction mixture was flushed with nitrogen. Afterward 1,1'-bis(diphenylphosphino)ferrocenepalladium(II) dichloride and dichloromethane ( $16.95 \mathrm{mg} ; 0.02 \mathrm{mmol}$ ) were added, and the mixture was stirred in the microwave for $90 \mathrm{~min}$ at $120{ }^{\circ} \mathrm{C}$. The reaction mixture was diluted with water and ethyl acetate. The organic layer was separated, washed with brine, dried, and the solvent was removed under reduced pressure. The crude product was purified using method P1 a, yielding $15 \mathrm{mg}(12 \%, 0.049 \mathrm{mmol})$ of the title compound. Purity by method A3: $>95 \%, t_{\mathrm{R}}=0.91 \mathrm{~min}$. MS $\left(\mathrm{ESI}^{+}\right) \mathrm{m} / z 307(\mathrm{M}+$ $\mathrm{H})^{+}$. HRMS $(\mathrm{m} / z)$ : $[\mathrm{M}]^{+}$calcd for $\mathrm{C}_{16} \mathrm{H}_{14} \mathrm{~N}_{6} \mathrm{O}, 306.1229$; found, 306.1223. ${ }^{1} \mathrm{H}$ NMR (DMSO- $\left.d_{6}, 500 \mathrm{MHz}\right): \delta=8.33(\mathrm{~s}, 1 \mathrm{H}), 8.24(\mathrm{~d}$, $J=9.8 \mathrm{~Hz}, 1 \mathrm{H}), 7.60(\mathrm{~d}, J=9.8 \mathrm{~Hz}, 1 \mathrm{H}), 7.37(\mathrm{br} \mathrm{t}, J=7.7 \mathrm{~Hz}, 2 \mathrm{H})$, 7.12 (br t, $J=7.4 \mathrm{~Hz}, 1 \mathrm{H}), 7.00(\mathrm{br} \mathrm{d}, J=8.2 \mathrm{~Hz}, 2 \mathrm{H}), 3.73(\mathrm{~s}, 3 \mathrm{H})$, $2.28 \mathrm{ppm}(\mathrm{s}, 3 \mathrm{H}) .{ }^{13} \mathrm{C}$ NMR (DMSO- $\left.d_{6}, 125 \mathrm{MHz}\right): \delta=156.3,147.3$, $146.7,146.4,142.9,138.8,130.6,125.2,124.0,119.3,115.5,104.9$, 35.1, 9.3 ppm.

Protein Expression and Purification. Recombinant human Brd4-BD1 (bromodomain 1 of bromodomain containing protein 4) was expressed in E. coli BL21(DE3) and contains an N-terminal TEVcleavable His6-tag. (The expression plasmid was kindly provided by Boehringer Ingelheim.) ${ }^{15} \mathrm{~N}$ labeled H6-TEV-Brd4-BD1 was expressed following the expression protocol for efficient isotopic labeling of recombinant proteins using a 4-fold cell concentration in isotopically labeled minimal medium. ${ }^{22}$ After resuspension in minimal medium, cells were put for $5 \mathrm{~min}$ on ice and $30 \mathrm{~min}$ at $18{ }^{\circ} \mathrm{C}$ before induction with $0.4 \mathrm{mM}$ IPTG (isopropyl- $\beta$-D-1-thiogalactopyranoside). Perdeuterated H6-TEV-Brd4-BD1 was expressed by transferring small volumes of E. coli BL21(DE3) cells carrying the expression plasmid from M9 medium (no labeled material, $100 \% \mathrm{H}_{2} \mathrm{O}$ ) to $\mathrm{M} 9^{50 \% \mathrm{D} 2 \mathrm{O}}$ medium (no labeled material, $50 \% \mathrm{D}_{2} \mathrm{O}, 50 \% \mathrm{H}_{2} \mathrm{O}$ ), and finally to 800 $\mathrm{mL}$ of $\mathrm{M} 9^{100 \% \mathrm{D} 2 \mathrm{O}}$ (no labeled material, $100 \% \mathrm{D}_{2} \mathrm{O}$ ). After reaching an $\mathrm{OD}_{600}$ of $0.7-0.9$, cells were centrifuged at $4000 \mathrm{~g}$ for $5 \mathrm{~min}$ at $20^{\circ} \mathrm{C}$, washed once with a small amount of $\mathrm{M} 9^{100 \% \mathrm{D} 2 \mathrm{O}}$ (no labeled material, $100 \% \mathrm{D}_{2} \mathrm{O}$ ) and again centrifuged at $4000 \mathrm{~g}$ for $5 \mathrm{~min}$ at $20^{\circ} \mathrm{C}$. The pellet was resuspended in $200 \mathrm{~mL}$ of $\mathrm{M} 9^{100 \% \mathrm{D} 2 \mathrm{O}}$ (containing $1 \mathrm{~g} / \mathrm{L}$ ${ }^{15} \mathrm{NH}_{4} \mathrm{Cl}$ and D-glucose-1,2,3,4,5,6,6- $\mathrm{d}_{7}$ ). Cells were put for $5 \mathrm{~min}$ on ice and $1 \mathrm{~h}$ at $18{ }^{\circ} \mathrm{C}$ before induction with $0.4 \mathrm{mM}$ IPTG (isopropyl- $\beta$ D-1-thiogalactopyranoside). Cells were collected after $18 \mathrm{~h}$ of expression at $18{ }^{\circ} \mathrm{C}$, and the pellet was resuspended in $40 \mathrm{~mL}$ of buffer containing $20 \mathrm{mM}$ sodium phosphate, $500 \mathrm{mM} \mathrm{NaCl}, 20 \mathrm{mM}$ imidazole ( $\mathrm{pH} 7.5$ ), 5\% glycerol, and protease inhibitor (Roche cOmplete Mini, EDTA free). Bacteria were lysed by sonication. Proteins were purified by $\mathrm{Ni}^{2+}$ affinity chromatography (HiTrap Chelating HP, $5 \mathrm{~mL}$, GE Healthcare), incorporating a high salt wash (buffer containing $1.5 \mathrm{M} \mathrm{NaCl}$ ), and cleaved with TEV protease overnight at $4{ }^{\circ} \mathrm{C}(20 \mathrm{mM}$ sodium phosphate, $500 \mathrm{mM} \mathrm{NaCl}, 2.5 \%$ glycerol, $2 \mathrm{mM} \beta$-mercaptoethanol). The cleaved protein was again loaded onto a $\mathrm{Ni}^{2+}$ column to bind the cleaved His6-tag and the His6tagged TEV protease and the flow-through containing Brd4-BD1 concentrated and loaded onto a gel filtration column equilibrated in 10 $\mathrm{mM}$ sodium phosphate, $100 \mathrm{mM} \mathrm{NaCl}(\mathrm{pH}$ 7.5) (HiLoad 16/60 Superdex 75pg, GE Healthcare). Brd4-BD1 containing fractions were concentrated in an Amicon Ultra-15 centrifugal filter device $3 \mathrm{~K}$ NMWL and stored at $-20{ }^{\circ} \mathrm{C}$.

NMR Spectroscopy. 1D, STD, and WaterLOGSY experiments were carried out at 277 and $298 \mathrm{~K}$ on a Varian Inova $500 \mathrm{MHz}$ spectrometer using a standard $5 \mathrm{~mm}{ }^{1} \mathrm{H}-{ }^{13} \mathrm{C}-{ }^{15} \mathrm{~N}$ triple-resonance probe head. NMR spectra for the characterization of small molecules were collected at $298 \mathrm{~K}$ on a Bruker Avance III HD $500 \mathrm{MHz}$ spectrometer. The system was equipped with a $5 \mathrm{~mm}$ TCI cryoprobe.

1D. 1D spectra were recorded with a double WATERGATE ${ }^{23}$ suppression element.

WaterLOGSY. The WaterLOGSY pulse sequence has been described before. ${ }^{4,24}$ Selective water inversion was achieved with a double excitation sculpting element employing water selective refocusing pulses (RE-BURP, ${ }^{25}$ inversion bandwidth of $0.5 \mathrm{ppm}$ ). The mixing time was set to $1 \mathrm{~s}$, incorporating a hard $180^{\circ}$ pulse in the middle of the mixing time and a water selective flip-back pulse at the beginning of the double WATERGATE water suppression module. The acquisition time and interscan delay were set to 1 and $2 \mathrm{~s}$, respectively. The number of scans was set to 2048. Sample concentrations were typically $1 \mathrm{mM}$ ligand and $0-45 \mu \mathrm{M}$ Brd4-BD1 in a buffer ( $10 \mathrm{mM}$ sodium phosphate, $100 \mathrm{mM} \mathrm{NaCl}, \mathrm{pH} 7.5$ ) containing $10 \% \mathrm{D}_{2} \mathrm{O}$. Intensity ratios $I_{\text {logsy }} / I_{1 \mathrm{D}}$ are derived from scaling 
of the 1D intensity to the corresponding LOGSY intensity with the Bruker TopSpin 3.5 pl5 software.

STD. STD experiments were performed in $\mathrm{H}_{2} \mathrm{O}$. STD-NMR spectra were acquired as a pseudo-2D version, interleaving on- and offresonance saturation. Selective saturation was achieved by a cascade of Gaussian pulses (bandwidth of $0.5 \mathrm{ppm}$, pulse length of $7.5 \mathrm{~ms}$, power of $15 \mathrm{~dB}$ ). On-resonance saturation was applied at $0 \mathrm{ppm}$ and offresonance saturation at $-42 \mathrm{ppm}$. A T1 $\rho$-filter of $50 \mathrm{~ms}$ was applied to eliminate protein resonances from the spectrum. The acquisition time and interscan delay were set to 0.5 and $4 \mathrm{~s}$, respectively. The number of scans for either on- or off-resonance saturation was set to 256 . Sample concentrations were $1 \mathrm{mM}$ ligand and $45 \mu \mathrm{M}$ Brd4-BD1 in a buffer (10 mM sodium phosphate, $100 \mathrm{mM} \mathrm{NaCl}, \mathrm{pH} 7.5)$ containing $10 \% \mathrm{D}_{2} \mathrm{O}$. STD amplification factors (STD-AF) were calculated as described before. ${ }^{1}\left(I_{\text {ref }}-I_{\text {sat }}\right) / I_{\text {ref }}$ needed for STD-AF calculation was derived from scaling of the $I_{\text {ref }}$ intensity to the corresponding STD intensity $\left(I_{\text {ref }}-I_{\text {sat }}\right)$ with the Bruker TopSpin $3.5 \mathrm{pl} 5$ software. Initial growth rate STD amplification factors $\left(\mathrm{STD}-\mathrm{AF}_{0}\right)$ were obtained by fitting STD-AFs measured at different saturation times $\left(t_{\text {sat }}=0.5,1,2\right.$, $3,4 \mathrm{~s}$ ) and calculated as described before. ${ }^{26}$

Small Molecule NMR Spectroscopy. Samples were dissolved in 600 $\mu \mathrm{L}$ of DMSO- $d_{6}$, and TMS was added as an internal standard. $1 \mathrm{D}{ }^{1} \mathrm{H}$ spectra were acquired with $30^{\circ}$ excitation pulses and an interpulse delay of $4.2 \mathrm{~s}$ with $64 \mathrm{~K}$ data points and $20 \mathrm{ppm}$ sweep width. $1 \mathrm{D}{ }^{13} \mathrm{C}$ spectra were acquired with broadband composite pulse decoupling (WALTZ16) and an interpulse delay of $3.3 \mathrm{~s}$ with $64 \mathrm{~K}$ data points and a sweep width of $240 \mathrm{ppm}$. Spectra were processed with Topspin 3.1 software from Bruker and analyzed with ACDlabs NMR workbook 2016.

Cocrystallization, Processing, and Refinement of BRD4-BD1 Ligand Structures. Recombinant protein of Brd4-BD1 for crystallographic studies was produced as formerly described. ${ }^{27}$ The protein was concentrated to a final concentration of $11 \mathrm{mg} / \mathrm{mL}$ in a buffer containing $10 \mathrm{mM}$ HEPES at pH 7.5 and $100 \mathrm{mM}$ sodium chloride.

Brd4-BD1 protein was incubated with $2 \mathrm{mM}$ ligand, and cocrystals in complex with ligand 1 and ligand 2 were grown by mixing $1 \mu \mathrm{L}$ of protein solution with $1 \mu \mathrm{L}$ of reservoir solution (29\% PEG $3350 \mathrm{w} / \mathrm{v}$, $200 \mathrm{mM}$ disodium malonate, and HEPES, $\mathrm{pH}$ 7.2) using the hanging drop vapor diffusion method at $293 \mathrm{~K}$. Crystals appeared after 4 days. Before flash-freezing in liquid nitrogen, the crystals were cryoprotected by the addition of ethylene glycol in the crystallization drop to a final concentration of $25 \%(\mathrm{v} / \mathrm{v})$.

Images were processed with autoPROC. ${ }^{28}$ The resolution limits were set using default autoPROC settings. The structures were solved by molecular replacement using the Brd4-BD1 structure 2OSS as a search model. Subsequent model building and refinement were done using standard protocols using $\mathrm{CCP} 4,{ }^{29} \mathrm{COOT}^{30}$ and autoBUSTER $^{31}$ Crystallographic data collection statistics and refinement statistics can be found in the Supporting Information (Tables S2 and S3).

Compound 1 (space group $=P 1$, unit cell $a=30.38 \AA, b=39.51 \AA$, $c=57.97 \AA, \alpha=99,71^{\circ}, \beta=105,05^{\circ}, \gamma=89,90^{\circ}$, resolution $=1.38 \AA$ ) was refined to $R / R_{\text {free }}=22.2 / 24.2 \%$ with $100 \%$ of the residues in Ramachandran allowed regions.

Compound 2 (space group $=P 22_{1} 2_{1} 2_{1}$, unit cell $a=37.26 \AA$, $b=$ 44.18 $\AA, c=78.49 \AA, \alpha=\beta=\gamma=90^{\circ}$, resolution $=1.65 \AA$ ) was refined to $R / R_{\text {free }}=18.7 / 21.4 \%$ with $100 \%$ of the residues in Ramachandran allowed regions.

\section{ASSOCIATED CONTENT}

\section{(S Supporting Information}

The Supporting Information is available free of charge on the ACS Publications website at DOI: 10.1021/acs.jmedchem. 7 b00845.

Description of the LOGSY-titration methodology and the extraction of LOGSY factors; simulation of LOGSYtitration intensities; comparison of LOGSY titrations with protonated and deuterated protein; table of compounds that show an affinity increase after introduction of a secondary amine; schemes for the synthesis of ligand $\mathbf{1}$ and ligand 2; crystallographic data collection and refinement statistics (PDF)

Molecular formula strings and $\mathrm{IC}_{50}$ values $(\mathrm{CSV})$

\section{Accession Codes}

Atomic coordinates of Brd4-BD1 bound to ligand 1 (5M39) and ligand 2 (5M3A) have been deposited in the Protein Data Bank. Authors will release the atomic coordinates and experimental data upon article publication.

\section{AUTHOR INFORMATION}

\section{Corresponding Author}

*E-mail: robert.konrat@univie.ac.at. Phone: +43-(0)1-427752202.

ORCID $\odot$

Leonhard Geist: 0000-0002-3241-676X

\section{Author Contributions}

L.G. performed the NMR experiments. L.G., M.M., and R.K. wrote the manuscript. M.M. and H.E. supervised the medicinal chemistry team. H.E. designed the synthetic strategies. D.K. and B.W. determined and analyzed the cocrystal structures. X.-L.C. performed the analysis on cocrystal structures. R.K. and D.B.M. supervised the study. All authors have given approval to the final version of the manuscript.

\section{Notes}

The authors declare no competing financial interest.

\section{ACKNOWLEDGMENTS}

The authors thank Dr. Andreas Zoephel for providing plasmids and protocols for Brd4-BD1 expression and purification, Teresa Adacker for writing the experimental section on the synthesis of the compounds, as well as Georg Kontaxis for pulse sequence programming and general NMR expertise. Funding for the work was provided by Boehringer Ingelheim and the Christian Doppler Laboratory for High-Content Structural Biology and Biotechnology, Austria.

\section{ABBREVIATIONS USED}

AFP-NOESY, adiabatic fast passage nuclear Overhauser effect spectroscopy; $\mathrm{BD}$, bromodomain; BET, bromodomain and extra-terminal; Brd4-BD1, bromodomain 1 of bromodomain containing protein 4; DIRECTION, difference of inversion recovery rate with and without target irradiation; GEM, group epitope mapping; ILOE, interligand nuclear Overhauser effect; INPHARMA, interligand nuclear Overhauser effect for pharmacophore mapping; NOE, nuclear Overhauser effect; SALMON, solvent accessibility, ligand binding, and mapping of ligand orientation by NMR; SAR, structure-activity relationship; STD, saturation transfer difference; STD-AF $\mathrm{F}_{0}$, initial growth rate saturation transfer difference amplification factor; WaterLOGSY, water ligand observed via gradient spectroscopy

\section{REFERENCES}

(1) Mayer, M.; Meyer, B. Group epitope mapping by saturation transfer difference NMR to identify segments of a ligand in direct

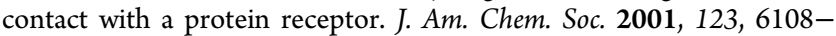
6117.

(2) Ludwig, C.; Michiels, P. J.; Lodi, A.; Ride, J.; Bunce, C.; Gunther, U. L. Evaluation of solvent accessibility epitopes for different dehydrogenase inhibitors. ChemMedChem 2008, 3, 1371-1376. 
(3) Dalvit, C.; Fogliatto, G.; Stewart, A.; Veronesi, M.; Stockman, B. WaterLOGSY as a method for primary NMR screening: practical aspects and range of applicability. I. Biomol. NMR 2001, 21, 349-359.

(4) Dalvit, C.; Pevarello, P.; Tatò, M.; Veronesi, M.; Vulpetti, A.; Sundström, M. Identification of compounds with binding affinity to proteins via magnetization transfer from bulk water. L. Biomol. NMR 2000, 18, 65-68.

(5) Dalvit, C.; Fagerness, P. E.; Hadden, D. T.; Sarver, R. W.; Stockman, B. J. Fluorine-NMR experiments for high-throughput screening: theoretical aspects, practical considerations, and range of applicability. I. Am. Chem. Soc. 2003, 125, 7696-7703.

(6) Shuker, S. B.; Hajduk, P. J.; Meadows, R. P.; Fesik, S. W. Discovering high-affinity ligands for proteins: SAR by NMR. $\underline{\text { Science }}$ 1996, 274, 1531-1534.

(7) Auer, R.; Kloiber, K.; Vavrinska, A.; Geist, L.; Coudevylle, N.; Konrat, R. Pharmacophore mapping via cross-relaxation during adiabatic fast passage. I. Am. Chem. Soc. 2010, 132, 1480-1481.

(8) Villicana, C.; Cruz, G.; Zurita, M. The basal transcription machinery as a target for cancer therapy. Cancer Cell Int. 2014, 14, 18.

(9) Ludwig, C.; Michiels, P. J.; Wu, X.; Kavanagh, K. L.; Pilka, E.; Jansson, A.; Oppermann, U.; Gunther, U. L. SALMON: solvent accessibility, ligand binding, and mapping of ligand orientation by NMR spectroscopy. I. Med. Chem. 2008, 51, 1-3.

(10) Mizukoshi, Y.; Abe, A.; Takizawa, T.; Hanzawa, H.; Fukunishi, Y.; Shimada, I.; Takahashi, H. An accurate pharmacophore mapping method by NMR spectroscopy. Angew. Chem. Int. Ed. 2012, 51, $1362-1365$.

(11) Ni, F.; Zhu, Y. Accounting for ligand-protein interactions in the relaxation-matrix analysis of transferred nuclear Overhauser effects. $I$. Magn. Reson. Ser. B 1994, 103, 180-184.

(12) Balaram, P.; Bothner-By, A. A.; Dadok, J. Negative nuclear Overhauser effects as probes of macromolecular structure. I. Am. Chem. Soc. 1972, 94, 4015-4017.

(13) Zeng, L.; Zhou, M. M. Bromodomain: an acetyl-lysine binding domain. FEBS Lett. 2002, 513, 124-128.

(14) Wu, S. Y.; Chiang, C. M. The double bromodomain-containing chromatin adaptor Brd4 and transcriptional regulation. I. Biol. Chem. 2007, 282, 13141-13145.

(15) Delmore, J. E.; Issa, G. C.; Lemieux, M. E.; Rahl, P. B.; Shi, J.; Jacobs, H. M.; Kastritis, E.; Gilpatrick, T.; Paranal, R. M.; Qi, J.; Chesi, M.; Schinzel, A. C.; McKeown, M. R.; Heffernan, T. P.; Vakoc, C. R.; Bergsagel, P. L.; Ghobrial, I. M.; Richardson, P. G.; Young, R. A.; Hahn, W. C.; Anderson, K. C.; Kung, A. L.; Bradner, J. E.; Mitsiades, C. S. BET bromodomain inhibition as a therapeutic strategy to target c-Myc. Cell 2011, 146, 904-917.

(16) Zuber, J.; Shi, J.; Wang, E.; Rappaport, A. R.; Herrmann, H.; Sison, E. A.; Magoon, D.; Qi, J.; Blatt, K.; Wunderlich, M.; Taylor, M. J.; Johns, C.; Chicas, A.; Mulloy, J. C.; Kogan, S. C.; Brown, P.; Valent, P.; Bradner, J. E.; Lowe, S. W.; Vakoc, C. R. RNAi screen identifies Brd4 as a therapeutic target in acute myeloid leukaemia. Nature 2011, 478, 524-528.

(17) Lockwood, W. W.; Zejnullahu, K.; Bradner, J. E.; Varmus, H. Sensitivity of human lung adenocarcinoma cell lines to targeted inhibition of BET epigenetic signaling proteins. Proc. Natl. Acad. Sci. U. S. A. 2012, 109, 19408-19413.

(18) Halle, B. Protein hydration dynamics in solution: a critical survey. Philos. Trans. $R$. Soc. B 2004, 359, 1207-1223 (discussion 1223-1224, 1323-1328).

(19) Ernst, J. A.; Clubb, R. T.; Zhou, H. X.; Gronenborn, A. M.; Clore, G. M. Demonstration of positionally disordered water within a protein hydrophobic cavity by NMR. Science 1995, 267, 1813-1817.

(20) Otting, G. NMR studies of water bound to biological molecules. Prog. Nucl. Magn. Reson. Spectrosc. 1997, 31, 259-285.

(21) Grzesiek, S.; Bax, A.; Nicholson, L. K.; Yamazaki, T.; Wingfield, P.; Stahl, S. J.; Eyermann, C. J.; Torchia, D. A.; Hodge, C. N. NMR evidence for the displacement of a conserved interior water molecule in HIV protease by a non-peptide cyclic urea-based inhibitor. $\underline{\text {. Am. }}$. Chem. Soc. 1994, 116, 1581-1582.
(22) Marley, J.; Lu, M.; Bracken, C. A method for efficient isotopic labeling of recombinant proteins. I. Biomol. NMR 2001, 20, 71-75.

(23) Piotto, M.; Saudek, V.; Sklenář, V. Gradient-tailored excitation for single-quantum NMR spectroscopy of aqueous solutions. L. Biomol. NMR 1992, 2, 661-665.

(24) Dalvit, C. Efficient multiple-solvent suppression for the study of the interactions of organic solvents with biomolecules. I. Biomol. NMR 1998, 11, 437-444.

(25) Geen, H.; Freeman, R. Band-selective radiofrequency pulses. J. Magn. Reson. (1969-1992) 1991, 93, 93-141.

(26) Angulo, J.; Enriquez-Navas, P. M.; Nieto, P. M. Ligand-receptor binding affinities from saturation transfer difference (STD) NMR spectroscopy: the binding isotherm of STD initial growth rates. Chem. - Eur. J. 2010, 16, 7803-7812.

(27) Filippakopoulos, P.; Picaud, S.; Mangos, M.; Keates, T.; Lambert, J.-P.; Barsyte-Lovejoy, D.; Felletar, I.; Volkmer, R.; Müller, S.; Pawson, T.; Gingras, A.-C.; Arrowsmith, C. H.; Knapp, S. Histone recognition and large-scale structural analysis of the human bromodomain family. Cell 2012, 149, 214-231.

(28) Vonrhein, C.; Flensburg, C.; Keller, P.; Sharff, A.; Smart, O.; Paciorek, W.; Womack, T.; Bricogne, G. Data processing and analysis with the autoPROC toolbox. Acta Crystallogr. Sect. D: Biol. Crustallogr. 2011, 67, 293-302.

(29) Winn, M. D.; Ballard, C. C.; Cowtan, K. D.; Dodson, E. J.; Emsley, P.; Evans, P. R.; Keegan, R. M.; Krissinel, E. B.; Leslie, A. G.; McCoy, A.; McNicholas, S. J.; Murshudov, G. N.; Pannu, N. S.; Potterton, E. A.; Powell, H. R.; Read, R. J.; Vagin, A.; Wilson, K. S. Overview of the CCP4 suite and current developments. Acta Crystallogr. Sect. D: Biol. Crystallogr. 2011, 67 (4), 235-242.

(30) Emsley, P.; Lohkamp, B.; Scott, W. G.; Cowtan, K. Features and development of Coot. Acta Crystallogr., Sect. D: Biol. Crystallogr. 2010, 66 (4), 486-501.

(31) Bricogne, G.; Blanc, E.; Brandl, M.; Flensburg, C.; Keller, P.; Paciorek, P.; Roversi, P.; Sharff, A.; Smart, O.; Vonrhein, C.; Womack, T. BUSTER, version 2.11.2; Global Phasing Ltd.: Cambridge, U.K., 2011.

\section{NOTE ADDED AFTER ASAP PUBLICATION}

Due to a production error, the version of this paper that was published ASAP October 1, 2017, contained an error in the Acknowledgments. The corrected version was reposted October 2, 2017. 